ARCHIVO ESPAÑOL DE ARTE, LXXXI, 323

JULIO-SEPTIEMBRE 2008, pp. 291-302

ISSN: 0004-0428

\title{
VARIA
}

\section{EL CICLO ESCATOLÓGICO DE LAS RECIENTEMENTE DESCUBIERTAS PINTURAS ROMÁNICAS DE SAN MIGUEL DE GORMAZ (SORIA)}

Al llevarse a cabo en 1996 el estudio para la restauración y (en desafortunada expresión, muy de moda en los medios político-culturales) "puesta en valor" de la abandonada ermita de San Miguel de Gormaz, salieron a la luz varios frescos de época medieval ${ }^{1}$. Estos frescos habían permanecido cubiertos hasta entonces por el acostumbrado revoco de cal. Aunque las primeras catas ${ }^{2}$ auguraban ya el carácter excepcional de las pinturas recién descubiertas ${ }^{3}$, su importancia no pudo ser totalmente evaluada hasta obtenerse, una vez completado el rompecabezas parietal, la visión panorámica, si bien aún defectuosa (en espera de su última y definitiva restauración ${ }^{4}$ ), de toda la superficie pintada.

${ }^{1}$ El 31 de octubre de 1997 el diario El Norte de Castilla daba la noticia de su descubrimiento en un artículo de la agencia Efe titulado: "Encuentran unas pinturas medievales de gran valor en San Miguel de Gormaz".

${ }^{2}$ Para un resumen de estos primeros pasos, cf. "Ermita de San Miguel de Gormaz (Soria)" y "Pinturas Murales de la Ermita de San Miguel. Gormaz (Soria)", en Fernández, J. J. (coord.), Castilla y León restaura. 1995-1999, Junta de Castilla y León, Valladolid, 1999, pp. 84-89 y 252-255.

${ }^{3}$ Las publicaciones de la Junta de Castilla y León hablan de pinturas al temple. Por su parte, Carmen RaLlo Gruss afirma: "Efectuados los correspondientes análisis, ha resultado tratarse de una pintura al seco en temple de cola, graso en algunos empastes". Al parecer, la analítica química ha sido realizada ex profeso para el estudio de la autora en el laboratorio de la Universidad Alfonso X, de Madrid (cf. Rallo Gruss, C., Aportaciones a la técnica y estilística de la pintura mural en Castilla a final de la Edad Media. Tradición e influencia islámica, FUE, Madrid, 2002, p. 19, not. 12). Sin querer poner en duda los resultados de esos análisis, esperamos que en un futuro muy próximo la empresa adjudicataria de los trabajos de restauración de las pinturas de San Miguel, o la misma Junta, lleve a cabo sus propias pruebas. Sería interesante cotejarlas con las nuevas informaciones que los distintos procesos de restauración están proporcionando de sus dos templos hermanos: San Baudelio de Berlanga y Maderuelo [cf. González Pascual, M. y Terés Navarro, E. (coords.), La ermita de San Baudelio de Berlanga: las pinturas de la bóveda: avance de su restauración, Junta de Castilla y León/Museo Numantino, Soria, 2001; EdwardS, H. G. M., et al., "Medieval Pigments in the Monastery of San Baudelio, Spain: A Raman Spectroscopic Analysis", en Applied Spectroscopy (Society for Applied Spectroscopy), vol. 55, n. ${ }^{\circ}$ 1, 2001, pp. 71-76; DALE Smith, G. y Clark, R. J. H., "Note on lead (II) Oxide in Medieval Frescoes from the Monastery of San Baudelio, Spain", en Applied Spectroscopy (Society for Applied Spectroscopy), vol. 56, n. ${ }^{\circ}$ 6, 2002, pp. 804-806; PAnZIERI, G. y GarCía Pérez-Mínguez, M. M., "Conservación y restauración de los restos de las pinturas murales de la ermita de la Vera Cruz de Maderuelo (Soria)", en la página web: www.maderuelo.com/ayuntamiento/informeveracruz.html. (consultada: 06/05/2004).

${ }^{4}$ El concurso para la "reintegración y acabado de paramentos y pinturas murales de la iglesia de San Miguel de Gormaz" ha sido publicado en el BOCYL de fecha 23 de septiembre de 2005. 
Tampoco se tardó mucho en comprobar que su estilo, indudablemente románico, coincidía con el de otras dos conocidas ermitas de la región: Maderuelo y San Baudelio de Berlanga, con las que forma -tanto por su extensión (más de $180 \mathrm{~m}^{2}$ ) como por su calidad- una trinidad pictórica de primer orden, digna, por otra parte, de la magnífica arquitectura castellano-leonesa.

\section{Arquitectura}

Alejada por su modesta arquitectura tanto del interés del público como del de especialistas y estudiosos (así lo atestiguan la escasa bibliografía y su tardía declaración como Bien de Interés Cultural $^{5}$ ), son las olvidadas pinturas de su interior las que han logrado rescatarla -como sucede con las dos ermitas antes citadas y con tantos otros humildes templos- del abandono en el que se hallaba.

A la hora de abordar su análisis debemos tener presentes las intervenciones a las que últimamente ha sido sometida su tectónica, pues sin duda son ellas, junto con los frescos objeto del presente estudio, las que están proporcionando una visión completamente nueva de esta ermita soriana. Un templo caracterizado por una mezcolanza constructiva un tanto atípica, en donde, además de combinarse estructuras y elementos de períodos diferentes, se reutilizan sin demasiados reparos materiales provenientes de otros monumentos ${ }^{6}$. Todo lo cual contribuye tanto a enriquecer su estudio como a dificultar la datación ${ }^{7}$.

Su sencillo perfil se configuraba originalmente en dos únicos cuerpos: una nave y su correspondiente cabecera, ambas cubiertas exteriormente a dos aguas, y de planta rectangular; la del ábside, cuasi equilátera. La fábrica de los muros, donde escasean los vanos, es de tosca y menuda mampostería, y se remata en los esquinales con pequeño sillarejo. La espadaña que se levanta en el hastial, con dos vanos de medio punto, y la galería porticada, adosada al costado meridional y ciega hasta su restauración ${ }^{8}$, son probablemente ajenas al proyecto primitivo ${ }^{9}$, que, por lo que se va descubriendo, correspondía a un templo prerrománico, tal vez visigótico ${ }^{10}$. La portada de entrada a la nave, importada de otro templo ${ }^{11}$, presenta una doble faceta, pues mientras en el exterior es de talla románica ${ }^{12}$, en el interior se corresponde con la puerta original del recinto, más pequeña y de arco de herradura.

Dentro ya de la ermita, vuelve a destacar, gracias a la eliminación de añadidos posteriores, la sobriedad de la que debió de ser su traza primigenia. La nave, asentada directamente sobre

\footnotetext{
53 de octubre de 1996.

${ }^{6}$ Lápidas romanas y árabes, y relieves de procedencia desconocida en los muros; sillares, dovelaje, columnas y capiteles en la portada, y, probablemente, algunas de las impostas del exterior del ábside.

${ }^{7}$ Elena Heras et al. suponen que la construcción de San Miguel de Gormaz se llevaría a cabo a mediados del siglo XI, cuando la fortaleza califal cayó en manos cristianas (cf. HerAs, E., et al., "San Miguel de Gormaz (Soria). Estudio y puesta en valor de un edificio histórico", en Actas del V Congreso de Arqueología Medieval Española, Junta de Castilla y León, Valladolid, 1999, vol. I, pp. 393-405).

${ }^{8}$ Hasta su actual restauración se creía que los arcos de la galería eran de herradura; sin embargo, han resultado ser de medio punto.

9 Jaime NUÑo GonZÁLEZ considera que la galería porticada probablemente no es ni románica ni medieval (cf. NUÑo GONZÁlEZ, J., op. cit., p. 539).

${ }^{10}$ La presencia de elementos de origen visigótico fue estudiada por Tegógenes ORTEGA en dos artículos publicados

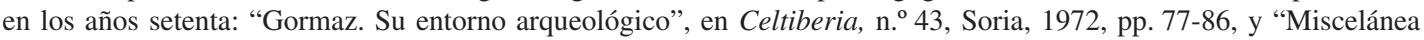
arqueológica soriana”, en XII Congreso Nacional de Arqueología. Jaén, 1971, Zaragoza, 1973, pp. 805-808.

11 Según Jaime NuÑo GonZÁlEZ, ibidem, la portada corresponde a la iglesia de Santiago, antigua capilla del cementerio.

${ }^{12}$ Con cuatro arquivoltas sencillas: dos lisas, una ajedrezada y otra de baquetón, las cuales descargan sobre cuatros columnas coronadas en capiteles toscamente figurados (cuadrúpedos afrontados, bulbos, etc.), haciéndolo las columnas a su vez sobre otros capiteles reutilizados como basas.
} 
el suelo de roca e iluminada únicamente por tres saeteras ${ }^{13}$, se cubre con armazón de madera, mientras que la cabecera lo hace por su parte con bóveda de cañón. En el testero se encuentra la única entrada de luz de la capilla: una pequeña saetera abocinada. El arco preabsidal consistía hasta las últimas obras en un amplio arco carpanel de perfiles barrocos. En el proceso restaurador se decidió su demolición y posterior sustitución por uno más acorde con la línea original del templo, para lo que se pensó como modelo en el triunfal de San Baudelio de Berlanga, aunque finalmente se optara por uno de medio punto. Por último, a los pies de la ermita, se encuentra un gran arco apuntado, de fábrica de sillería y de prácticamente la misma luz que la nave; y, como la espadaña y la galería porticada, de data más tardía.

\section{Panorámica iconográfica}

\section{Ábside}

En la boquilla de la bóveda se representa una gran Maiestas Domini, inscrita como es habitual en la correspondiente mandorla, que es, en este caso, muy apuntada. En los derrames, ocho ángeles, cuatro en cada flanco, acompañan al Cristo en majestad. Los muros laterales se completan por su parte con ocho de los veinticuatro ancianos del Apocalipsis, mientras que, en el medio punto del testero, todavía se pueden observar, como en Maderuelo y en San Baudelio, dos ángeles que sostienen un medallón del Agnus Dei, al que dos figuras arrodilladas (Abel y Melquisedec) presentan sus ofrendas. La paloma del Espíritu Santo preside la clave de la saetera, flanqueada a cada lado de la ventana por otros dos ancianos. En el muro de entrada, y separados por el arco triunfal, se disponen otros cuatro ancianos apocalípticos, y sobre ellos, en el semicírculo superior, apenas entrevistas, pues su estado de conservación no es muy bueno ${ }^{14}$, la Dormición de Adán y el Nacimiento de Eva. Un perímetro de cortinajes, estampados como en San Baudelio con grandes medallones de animales, recorre por último toda la zona inferior de la capilla.

\section{Nave}

Muro norte: los frescos de esta pared, al igual que los de su frontera, se distribuyen en tres registros. En el superior, de este a oeste, sobre fondos de fajas variadas, un ciclo con pasajes de la Infancia de Cristo: Anunciación, Visitación, Anuncio a los pastores y Nacimiento, y, colindando con el testero de la nave y amparada por un arco, una figura masculina, nimbada y sedente, probablemente San José.

El registro intermedio se inicia igualmente con otra figura nimbada, aunque ahora de pie y con ropajes eclesiásticos. A continuación se enfrentan dos grupos de jinetes encuadrados entre una pareja de torres cilíndricas. Por las ventanas de ambos torreones asoman pequeñas cabezas humanas. Junto al primero puede observarse un arquero que, a pie, dispara sus flechas contra los enemigos, mientras otro personaje, parapetado sobre la segunda fortificación, sopla un gran corno. El registro se cierra, por último, con un motivo que no deja de ser incoherente, al menos a primera vista, con la escena anteriormente descrita, pues se trata de una Visitatio sepulchri.

${ }^{13}$ Una en el testero de la nave, y las otras dos distribuidas asimétricamente (hacia la mitad este), en la zona superior de los paramentos norte y sur.

14 Toda la capilla fue repicada en su día para poder aplicarle un nuevo revoco, lo que se traduce en una lectura difícil y poco placentera de las imágenes. Como es lógico, aún no conocemos qué criterios se van a adoptar cuando se lleve a cabo la definitiva restauración de los frescos, y si éstos permitirán, respetando en la medida de lo posible las pinturas originales, que el futuro espectador obtenga, con menos esfuerzo del que hoy se le exige, una percepción más asequible de su iconografía. 
En el registro bajo, hoy desaparecido, debían de desplegarse, como en la cabecera de la ermita y en el muro sur, amplios cortinajes gríseos, decorados con medallones de animales.

Muro sur: en el registro superior continúa el ciclo de Navidad con los Magos ante Herodes y la Matanza de los Inocentes; en el intermedio, las escenas de ultratumba, objeto del presente estudio, y en el inferior, como en la capilla absidal, fragmentos de cortinajes.

Testero: de esta zona de la ermita no queda ningún resto de pintura, aunque Nuño González ${ }^{15}$ supone, con buen criterio, que pudo haber sido decorada con pasajes de la Pasión, Muerte y Resurrección de Jesucristo.

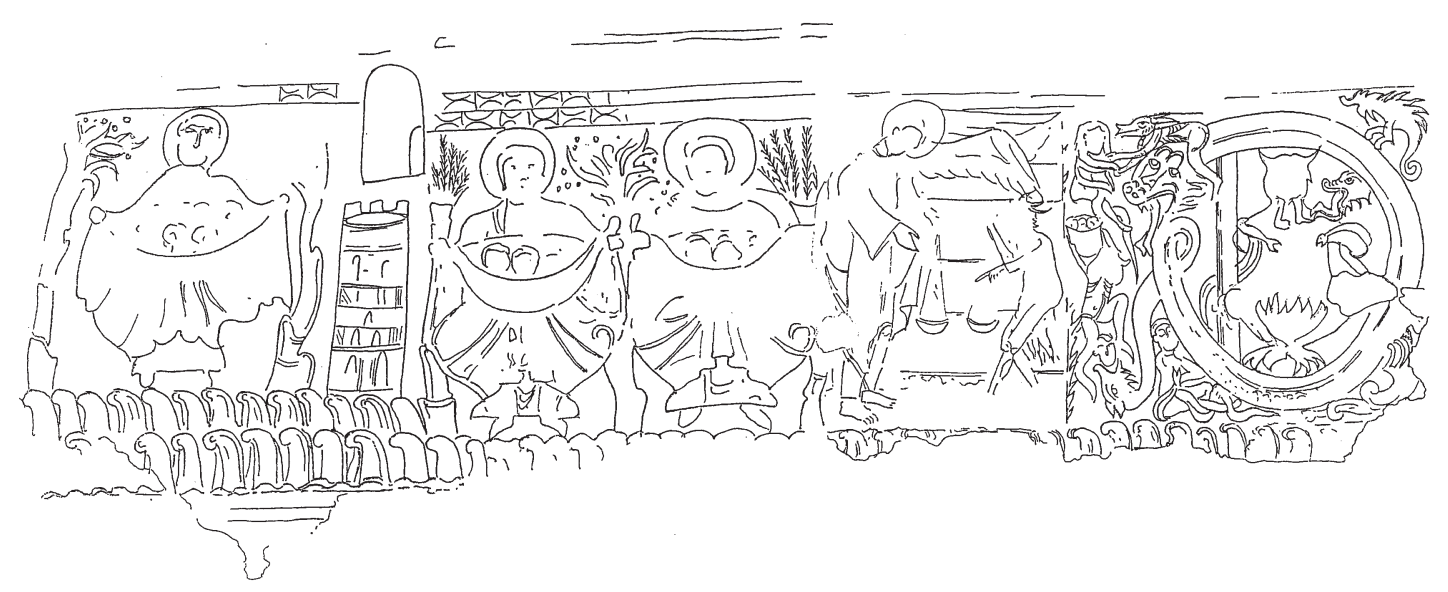

Fig. 1. El ciclo de Ultratumba.

\section{El seno de Abraham}

"Sinus Abrahae, Paradisus est" (Santo Tomás de Aquino, Catena aurea in Lucam, cap. XVI, lec. 5)

El registro se halla enmarcado superiormente por una fimbria de motivos geométricos (módulos cuadrangulares en cuyo interior se ajustan parejas de semicírculos tangentes), mientras que, por abajo, se asienta sobre un horizonte de iconos montañosos (o "montículos heráldicos", como los denomina Ourse ${ }^{16}$ ), iguales a los que pueden ser observados en la ermita berlanguesa. Estos iconos surgen a veces como representación "naturalista" de rocas o montañas, aunque en otras ocasiones parecen adoptar un papel que remite a topografías de carácter trascendente, como sospechamos que ocurre aquí, puesto que sobre ellos se va a desplegar el ciclo con representaciones de la vida de ultratumba: El Seno de Abraham, la psicostasis y el infierno.

Efectivamente, efectuando la lectura de izquierda a derecha, esto es, de este a oeste, hallamos la representación del Seno de Abraham. El fondo del panel es blanco, lo que podría relacionarse con la índole paradisíaca de este motivo iconográfico, pues frente a la opinión de Oursel ${ }^{17}$, que atribuye el albo fondo en las escenas edénicas de Maderuelo a una hipotética influencia leone-

15 NUÑo GONZÁLEZ, J., op. cit., p. 546.

16 Oursel, R., La pintura románica, Ediciones Encuentro, Madrid, 1981, p. 93.

17 Oursel, R., op. cit., p. 156. 
$\mathrm{sa}^{18}$ (dudosa influencia que, lógicamente, debería ser extensible a estos frescos de San Miguel de Gormaz), no creemos casual que la ermita segoviana reservara el blanco de cal sólo y exclusivamente para las escenas paradisíacas de la Creación de Adán y la Primera caída ${ }^{19}$. Integran la composición tres figuras nimbadas: el propio Abraham, Isaac y Jacob ${ }^{20}$ (figs. 2 y 3), las tres sedentes, y con cabellos y barbas blancos ${ }^{21}$. El primero se encuentra flanqueado por una pareja de árboles ${ }^{22}$ estilizadamente ecotados, de reducida copa y ramas anguíneas, de las que penden abundantes frutos $^{23}$ (ambas representaciones dendroideas se atienen a la misma morfología de sus dos ermitas hermanas), como corresponde a la idea paradisíaca de los primeros siglos de cristianismo e igualmente a la feracidad del jardín coránico. Abraham sostiene sobre sus rodillas, al igual que sus dos compañeros, el lienzo ${ }^{24}$ o hatillo psicopómpico, que actúa como receptaculum animarum; de él sobresalen pequeñas cabezas, símbolos de las almas bienaventuradas. Un torreón almenado ${ }^{25}$, muy del estilo de Berlanga y Maderuelo, separa a Abraham de los otros patriarcas $^{26}$, parejamente tratados, con sólo ciertas variaciones en el color de los ropajes. Isaac y Jacob se encuentran divididos a su vez por un nuevo árbol, y enmarcados, exteriormente, por otras dos figuraciones dendriformes de especie completamente diferente a la de los ubérrimos frutales. Se trata en concreto de dos palmeras muy estilizadas, pintiparadas de la que brota en medio del Edén de Maderuelo ${ }^{27}$.

${ }^{18}$ Obviamente, se refiere al fondo blanco sobre el que se disponen todas las escenas de San Isidoro de León, del que están ausentes las habituales fajas de color.

${ }^{19}$ El blanco, cuando se inserta como fondo en un contexto (de fajas de color) en el cual no es previsible, y además lo hace dentro de una topografía ultraterrena, parece sugerir, como más tarde lo harán los fondos áureos, "dimensiones infinitas".

${ }^{20}$ Cf. Grabar, A., Las vías de la creación en la iconografía cristiana, Alianza Editorial, Madrid, 1985, pp. 159160. Teresa Pérez Higuera señala que la incorporación de Isaac y Jacob al Seno de Abraham se debe a que "Cristo habló del Reino de los Cielos como un banquete celebrado con Abraham, Isaac y Jacob (Mt. VIII, 11)" (cf. PÉrEZ Higuera, T., "El Jardín del Paraíso: Paralelismos iconológicos en el arte hispanomusulman y cristiano medieval", en $A E A$, n. $^{\circ} 241,1988$, not. 16, p. 40). Por su parte, Beato vio en Abraham la figura de Dios Padre, en Isaac la de Cristo y en Jacob la de la Iglesia (cf. Comentario al Apocalipsis, II).

${ }^{21}$ Según Réau, Abraham habría sido, de acuerdo con la tradición, el primer hombre al que se le encanecieron los cabellos y las barbas (cf. RÉAU, L., Iconografía del arte cristiano. Iconografía del Antiguo Testamento, Ediciones del Serbal, Barcelona, 1996, p. 156). Por su parte, para Jérôme Baschet, las barbas de Abraham, además de ser símbolo de virilidad y fecundidad, contribuyen a acentuar su carácter de ancestro paternal; es decir, de Abraham como padre de todos los creyentes (cf. BASCHET, J., Le sein du père. Abraham et la paternité dans l'occident medieval, Gallimard, París, 2000, p. 146).

22 "La présence d'arbres autour de lui, renvoie d'abord au jardín paradisiaque et caractérise le lieu où se tient Abraham comme séjour de béatitude, d'abondance et fertilité" (BASCHET, J., op. cit., p. 147).

${ }^{23}$ Símbolos de las recompensas celestiales.

24 Jérôme BASCHET califica al Seno de Abraham, en acertada metáfora por su reiterada utilización de la tela psicopómpica y aun de sus propios ropajes, como "paradis textile" (BASCHET, J., op. cit., p. 26).

${ }^{25}$ Este torreón fue una de las primeras imágenes descubiertas al efectuar las catas. En un primer momento, cuando aún no era posible una visión global del conjunto, se lo consideró una representación del propio castillo de Gormaz, y los iconos montañosos, sin duda por su perfil ondulado, como el río Duero. En nuestra opinión, la inserción de esta torre adquiere sentido sólo como referente paradisíaco; es decir, en función de sucinto icono del paraíso como lugar protegido y cerrado, propio tanto del cristianismo como del Islam; esto es, como emblema de la Jerusalén Celestial, la siempre amurallada, encarnación simbólica del paraíso escatológico cristiano, o como una de las torres del paraíso muslímico (cf. Libro de la escala de Mahoma, cap. XXX, Ed. Siruela, Madrid, 1996, p. 82).

${ }^{26} \mathrm{Y}$ también una de las saeteras que iluminan la nave.

${ }^{27}$ Cook y Gudiol interpretaron, erróneamente, como un "tronco nudoso", la palmera que se interpone entre las dos famosas escenas del ábside de Maderuelo (Creación de Adán y Primera Caída), similar en todo a las que ahora nos ocupan (cf. SPEncer CoOK, W. W. y Gudiol Ricart, J., "Pintura e imaginería románicas", en Ars Hispaniae, t. VI,

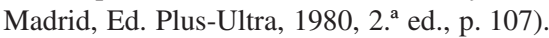



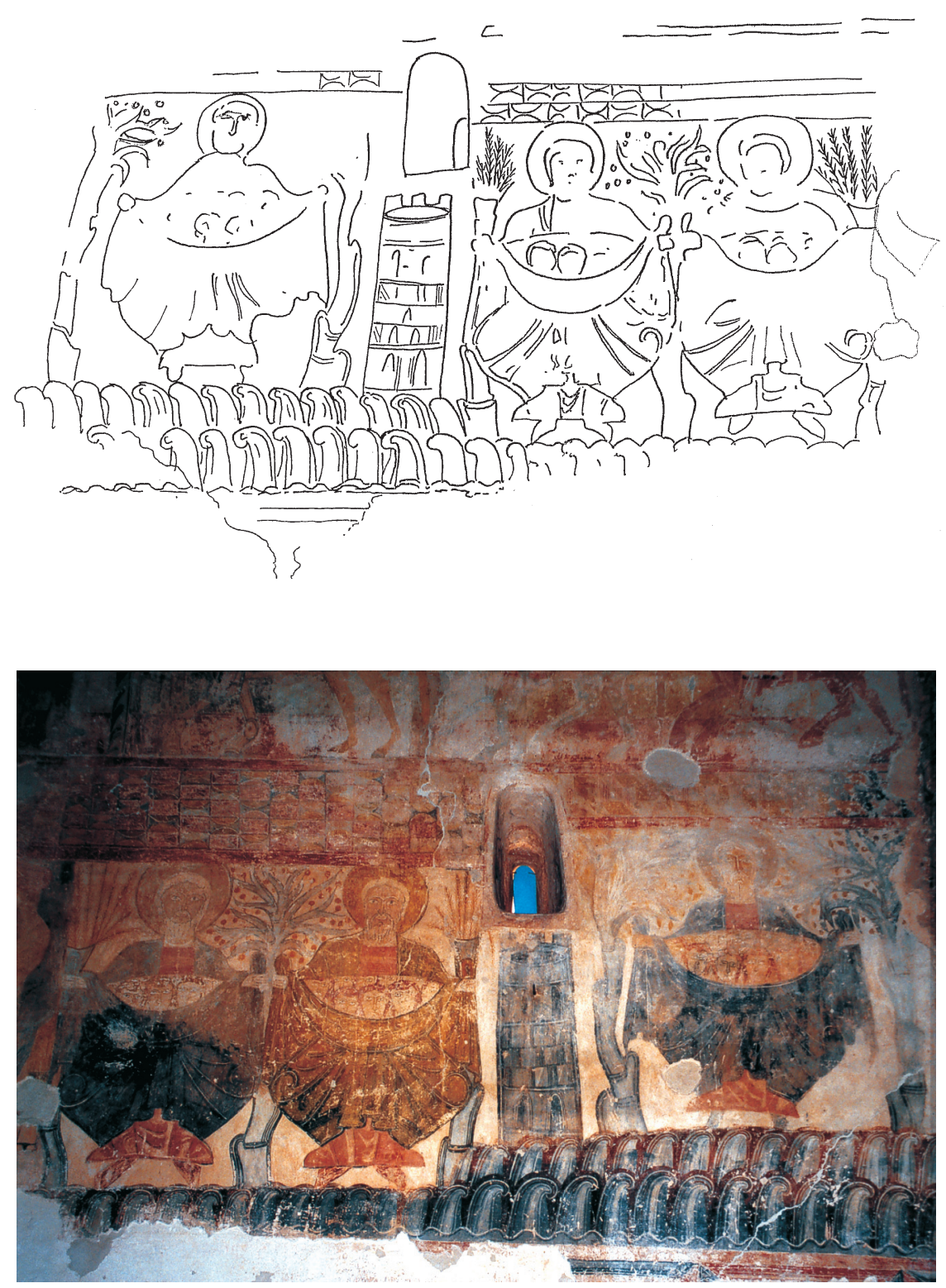

Figs. 2 y 3. El Seno de Abraham.

El Seno de Abraham apareció primeramente como motivo escatológico judío ${ }^{28}$. Ya en el mundo cristiano, sería asumido iconográficamente por el arte bizantino, donde, siempre sin abandonar la etérea concepción de las recompensas celestiales propia del cristianismo (en contraste directo

28 Aunque no apareciese en el Antiguo Testamento, el Seno de Abraham era para el pensamiento rabínico una de las dos partes en las que se dividía la mansión de los muertos. En este contexto, la estancia en el Seno de Abraham equivalía a la felicidad post mortem de los justos. 
con la musulmana, tan zafiamente prosaica para el pensamiento cristiano $^{29}$ ), se presentará ligado al Juicio Final, a la vida del Más Allá y al Paraíso. Su significado ha ido variando a lo largo de los siglos, sin perder, no obstante, algunas de sus características esenciales. Así, mientras Tertuliano ${ }^{30}$ creía que los justos debían conformarse con su estancia en el Seno de Abraham, ya que el verdadero paraíso estaba reservado sólo para los mártires, otros Padres de la Iglesia lo consideraban como un locus cuasi subterráneo ${ }^{31}$, situado entre el cielo y el infierno, una especie de Limbo patrum en donde los profetas y patriarcas del antiguo Israel ${ }^{32}$ aguardaban la venida del Mesías (venida que les abriría las puertas del definitivo reino de los cielos), y también, por extensión, como Sedes iustorum, es decir, como receptáculo destinado al consuelo de los justos en espera de su resurrección final ${ }^{33}$. En otras ocasiones fue visto como lugar de reposo y paz perpetua ${ }^{34}$ o como secretum destinado a los pobres bienaventurados; esto último en referencia directa al episodio lucano del pobre Lázaro y el rico epulón ( $L c$. XVI, 19) ${ }^{35}$. En cualquier caso, implícita o explícitamente, acabaría siendo asimilado al Paraíso ${ }^{36}$; aunque manteniendo relativamente constantes algunos de sus rasgos más representativos, como la interinidad (refrigerium interim) y el reposo (quies).

En el mundo islámico, donde este tema se halla igualmente presente (Abraham fue el tercero de sus profetas, después de Adán y Noé37), vino a ser asimismo una especie de limbo en el que eran recogidas las almas de los niños muertos sin uso de razón ${ }^{38}$. Las palmeras, dentro de este contexto, son claros símbolos paradisíacos, como lo son igualmente en Maderuelo y en Berlanga. En efecto, la palmera desarrolla esta simbología sobre todo dentro de las coordenadas islámicas, donde se manifiesta, junto con el granado, como uno de sus árboles sagrados ${ }^{39}$. En el cristianismo, su presencia, aunque escriturísticamente reducida al salmo XCI ("El justo florecerá como la palmera"), alcanzaría cierto desarrollo en contextos muy concretos. Por ejemplo, desempeñará un papel protagonista en algunas conocidas ilustraciones de los Beatos ${ }^{40}$, muchas veces impregnadas de un profundo simbolismo místico. Su aparición en estos manuscritos se explica porque Beato, el fogoso monje lebaniego, al comentar el texto apocalíptico de San Juan intercaló un pasaje exegético de los Moralia in Job de San Gregorio. En dicho pasaje el santo recurría al salmo ya comentado para hacer de la palmera símbolo del justo y su salvación, hasta el punto de identificarla con la cruz de Cristo ${ }^{41}$. En la iconografía escatológica cristiana aparecerá también, influida por

\footnotetext{
${ }^{29}$ Como de "lupanar et locus obscenissimus" califica Eulogio al paraíso coránico por las vírgenes prometidas a los bienaventurados seguidores de Mahoma (Memoriale sanctorum, I, 7).

${ }^{30}$ Contra Marcionem, IV, 34, P.L., II, col. 444.

31 SAN Agustín niega que se trate de una región subterránea aunque se sitúe próxima al infierno (De Genesi ad litteram, XII, 33). Sin embargo, como señala Jérôme BASCHET, en los siglos XII y XIII es posible encontrar aún diversas referencias a esta localización (BASCHET, J., op. cit., p. 102).

32 "Iam sinus Abrahae intellegitur secretum Patris" (SAN Agustín, Quaestionum Evangeliorum secundum Lucam, Lib. II, 38).

33 San Agustín, Quaestionum Evangeliorum secundum Lucam, lib. II, 38: "Ubi etiam ante resurrectionen iustorum animae vivunt cum Deo". Cfr. también De Genesi ad litteram, II, 33 y 34.

${ }^{34}$ Cfr. Ambrosio, De obitu Valentiniani, 71-72 y De Paradiso, 1, 4-5.

35 SAn Agustín, Serm. 14, 4-5 y Quaestiones Evangeliorum, II, cap. 38: "Sinus Abrahae, requies beatorum pauperum, quorum est regnun coelorum, in quo post hanc uitam recipiuntur" (P. L. XXXV, col. 1350).

${ }^{36}$ Cfr. Guiance, A., Los discursos sobre la muerte en la Castilla medieval. Siglos (VII-XV), Junta de Castilla y León, Valladolid, 1998, pp. 169-170.

37 Abraham (Ibrahim) es tenido como el padre de los árabes, pues ellos mismos, al considerarse descendientes de uno de sus hijos, Ismael, se autodenominan ismaelitas. En el Libro de la escala de Mahoma, XVII, es Abraham el que describe a Mahoma la forma del Paraíso, y en el Corán son numerosos los versículos dedicados a su figura.

${ }^{38}$ Cfr. Asín Palacios, M., Dante y el Islam, Ed. Voluntad, Madrid, 1927, p. 33.

39 Libro de la escala de Mahoma, XLIV.

40 Beato de Osma, Beato de Gerona, Beato del Museo Arqueológico Nacional, etc.

41 "La palma es la cruz de Cristo, la cual, mostrándose dura y rugosa en su corteza, nos da frutos dulcísimos que conducen a la salvación" (cit. en ChURRUCA, M., Influjo oriental en los temas iconográficos de la miniatura española.
} 
lo musulmán, asociada al paraíso ${ }^{42}$ en su doble acepción: edénica (Paradisus terrestris) y escatológica (Paradisus caelestis), como puede comprobarse en el Psalterio de Arenberg (primera mitad del siglo XIII), en las pinturas románico-bizantinas de Santo Angel in Formis, en una ilustración de las Cantigas de Santa María, o en el Beato de Valcavado (fol. 111), donde la palmera subraya doblemente su significado paradisíaco al convertirse en emblema de los bienaventurados que se cobijan bajo su copa con ramos en las manos ${ }^{43}$. Estos ramos tienen su referente en el libro del Apocalipsis (VII, 9), donde los elegidos por el Cordero aparecen vestidos de blanco "et palmae in manibus".

\section{La psicostasis}

Dispuesta entre los dos ámbitos del postmundum (paraíso e infierno) a los que irán destinadas las almas después de ser juzgadas, se puede contemplar con relativa nitidez, sobre un fondo que retoma las conocidas fajas de color del resto de las pinturas, la representación de una psicostasis o pesaje escatológico (figs. 4 y 5), tema de raíces muy diversas ${ }^{44}$, pero igualmente del interés de la escatología muslímica ${ }^{45}$. San Miguel, el encargado secular de esta tarea, da la espalda a las figuras patriarcales; una manera muy románica de separar dos escenas contiguas sin recurrir a ninguna clase de enmarcamiento. Su disposición, tanto por ello como por la mezquindad del espacio en el que se inserta, es considerablemente forzada, especialmente la de la cabeza, muy inclinada, casi horizontal, y la de las alas, por sus propias dimensiones aún más difíciles de encajar dentro del panel; las piernas, sin embargo, no se entrecruzan (lo que suele ser un sólito gesto del arcángel psicostático ${ }^{46}$ ) mientras las manos sujetan la balanza, que aparece vacía y en perfecto equilibrio. Se trata, pues, estrictamente hablando (si adoptamos la terminología de Yarza ${ }^{47}$ ), de

Siglos X al XII, Espasa Calpe, Madrid, 1939, p. 63). Por su parte el Bestiario de Aberdeen la identifica con el propio Cristo: "Hec palma est Christus" (fol. 33r).

42 Cfr. Teresa PÉrez Higuera, op. cit.

43 El ya mencionado Bestiario de Aberdeen proclama que los ramos de la palmera son los santos que gozan de la bienaventuranza eterna: "Et rami, id est sancti in eterna felicitate gloriantur" (fol. 33r).

${ }^{44}$ Egipcias, griegas, etc. Según Albert E. ElsEn la psicostasis, presente en el Juicio Final, tiene tal vez su origen patrístico en el siguiente texto de SAN AgUSTín, del que por otra parte no da ninguna referencia: "Las acciones buenas y malas estarán suspendidas en una balanza, y si preponderan las malas, el culpable será arrastrado al Infierno" (cf. Elsen, A. E., Los propósitos del arte, Aguilar, Madrid, 1971, p. 53).

45 "El día de la Resurrección pondremos las balanzas justas y no será vejada ninguna alma, y aunque fuese en el peso de un grano de mostaza, lo traeríamos" (Corán, XXI, 48) / "Dios ordenará que se traiga ante su presencia una balanza, cuyo fiel mide de longitud cuanto hay desde el oriente hasta el occidente; cada uno de sus dos platillos es tan grande que tapa todo el universo: uno de ellos es de claridad y el otro de tinieblas; el platillo de claridad está a la derecha de Dios y el de tinieblas, a la izquierda. En el platillo de claridad se colocarán los bienes y en el de tinieblas, los males... El hombre colocará en una cubeta sus propios bienes y en la otra, sus pecados cometidos..." (Libro de la escala de Mahoma, LXXIV) I "Cuando Dios pida cuentas al siervo y la balanza se incline con sus pecados más que con sus obras buenas, lo mandará al fuego" (Abu I-Hasan al-As'ari, Kitab sayarat al-yaqin. Tratado de escatología musulmana, XXXV, 90r. Traducción, estudio y notas a cargo de Concepción CASTILlo CASTILlo, Instituto Hispano-árabe de Cultura, Madrid, 1987).

${ }^{46}$ Nos referimos a las piernas entrecruzadas. Manuela CHURRUCA encuentra referencias de ese gesto en distintas escenas del claustro silense; referencias casi siempre vinculadas con situaciones extáticas, por ejemplo: los apóstoles en la venida del Espíritu Santo, en la Ascensión, en la aparición después de la Resurrección, etc. (ChURRUCA, M., op. cit., p. 38). Joaquín YARZA LUACES lo señala también como una de las fórmulas estéticas propias no sólo de las esculturas de Silos y Toulouse, sino igualmente de Moissac (una de las razones esgrimidas a veces para defender la dependencia de Silos respecto de Moissac), y supone, además, que su fuente original debe de hallarse en algunas ilustraciones francesas más o menos contemporáneas del claustro burgalés (cf. YARZA LuACES, J., "San Miguel y la balanza. Notas iconográficas a cerca de la psicostasis y el pesaje de las acciones morales", en Formas artísticas de lo imaginario, Ed. Anthropos, Barcelona, 1987, p. 120 y not. 3: pp. 148-149). Este posible origen galo había sido ya señalado por Meyer SCHAPIRO (cf. SCHAPIRO, M., "Del mozárabe al románico en Silos", en Estudios sobre el románico, Alianza Editorial, Madrid, 1984, p. 77).

${ }^{47}$ Op. cit., pp. 120 y 143. 

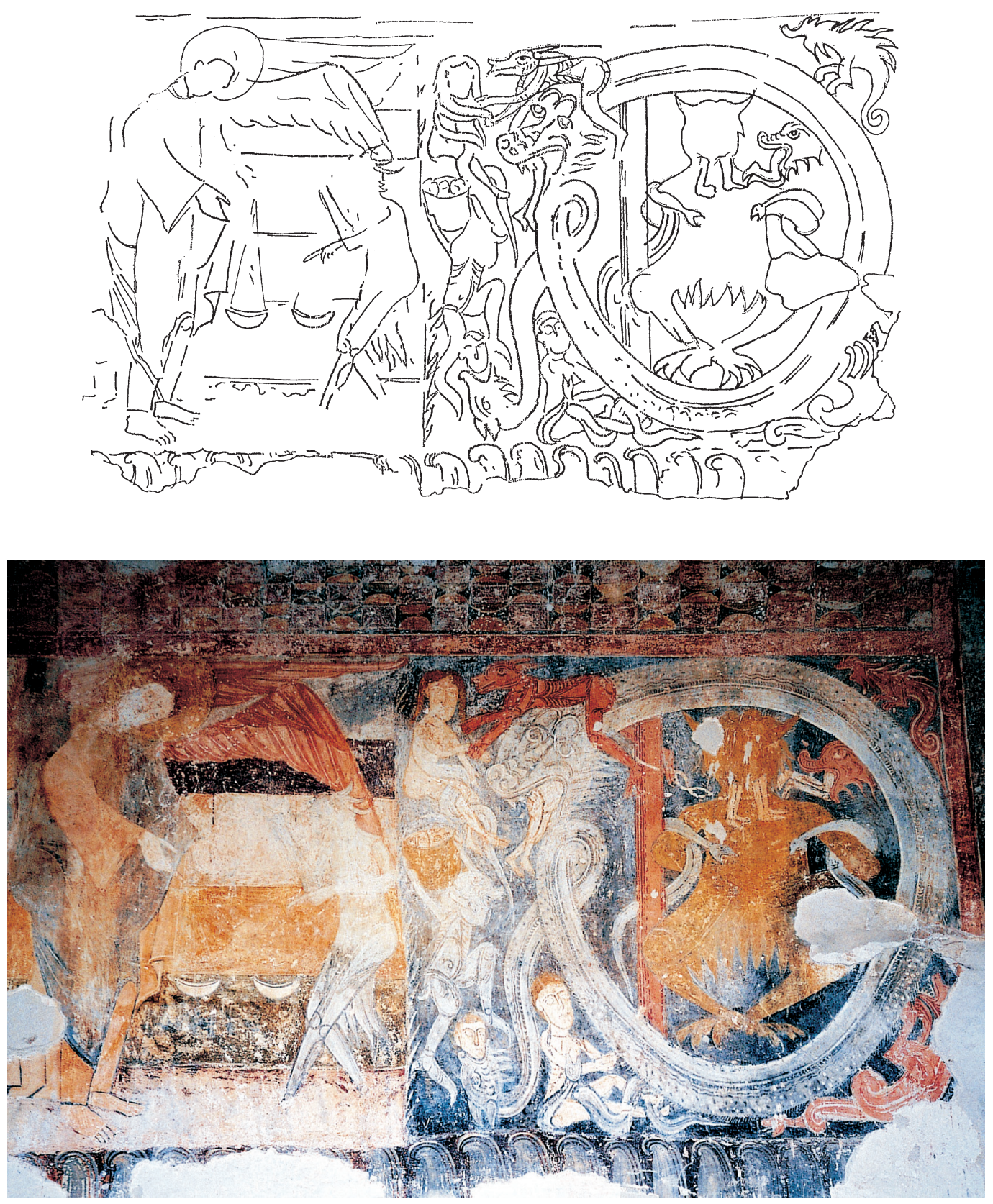

Figs. 4 y 5. La Psicostasis / El Infierno.

una pseudopsicostasis, ya que, al no observarse en los platillos de la statera las cabecillas u homúnculos con los que se suelen representar las almas, la acción no correspondería al pesaje de éstas (es decir, a una psicostasis en sentido estricto), sino a una de sus variantes, en la que lo que se somete a ponderación no son las almas, sino las buenas o malas acciones. Cierra la escena un diablo gris, de menor presencia que el arcángel, con quien disputa, como lo indica la quironomía 
en adlocutio de su mano derecha, en taimada maniobra de distracción para inclinar a su favor, cum sinistra manu, el fiel de la balanza.

\section{El infierno}

"Draco serpens est, id est, Diabolus" (Beato de Liébana, Comentarios al Apocalipsis, II)

Un escueto perfil, entre flamígero y pectiforme, da paso a la representación del infierno y sus penas; sin duda la escena más llamativa no sólo del ciclo de ultratumba, sino también de San Miguel de Gormaz en su conjunto y, posiblemente, de toda Castilla y León.

Sobre un fondo oscuro, como corresponde a tal lugar de perdición ("donde el sol de justicia, Cristo, no difunde su luz" ${ }^{48}$ ), un enorme monstruo andrófago (figs. 4 y 5) en forma de dragón-serpiente (manifestación teriomórfica del propio infierno) describe con su flexible y áptero cuerpo una amplia curva que no llega a cerrarse ${ }^{49}$. Sobre su cabeza cabalga un diablo cinocéfalo, cuyo color rojo contrasta con el frío gris del averno. Este engendro demoníaco tira con ahínco de la cabellera de una de las condenadas ${ }^{50}$ (probablemente infernada por impúdica o lasciva ${ }^{51}$ ), a la que atormentan, además, como al resto de las almas que allí penan sus culpas, diversas serpientes. Por su parte, el gran leviatán engulle a otro réprobo con la pequeña cabeza que nace del extremo de su cola. En el interior del circuloide descrito por su cuerpo, se inscribe una gran figura de Satanás, sin alas, sorprendentemente, amarillo, de poderosa, greñuda y cornígera cabeza, garras en los pies y brazos serpentígeros. Este gran demonio, en el que parecen fundirse los rasgos de sus dos congéneres del Beato de Fernando I y el Beato de Gerona ${ }^{52}$, devora a uno de los precitos, como lo hace también a su lado una grotesca y rúbea cabeza. Cada una de las dos enjutas del margen derecho se completa con un pequeño dragón ${ }^{53}$ rojo de cadenciosos roleos. Por último, junto al borde izquierdo del panel, un diablo leucofeo, de menor porte y distinta morfología que la del gran Satán central, ajoba un caldero lleno de nuevas almas destinadas al martirio eterno. El elemento más extraño de toda la composición no está constituido, sin embargo, por ninguna criatura real o imaginaria, sino por la franja rectangular que atraviesa verticalmente, sin rebasarlos, los límites curvilíneos del serpentón tartáreo, dividiendo de ese modo, asimétricamente, la superficie interior de la gehena.

48 "Ubi sol iustitiae Christus lumen non effundit in hoc puteo obsconsus iacet diabolus", Beato de Liébana, Comentario al Apocalipsis, lib. II. La oscuridad y negrura del infierno se hallan igualmente presentes en la gehena musulmana.

49 En el apócrifo Descensus ad inferos, el infierno se concibe ya como un monstruo devorador.

50 “¡Oh juventud, oh elegancia que es conducida al infierno! ¡Cuántas mujeres de mi comunidad serán cogidas por sus trenzas y conducidas al fuego!” (Abu I-Hasan al-As'ari, Kitab sayarat al-yaqin. Tratado de escatología musulmana, XL, 101r). Concepción CASTILlo señala, en la nota n. ${ }^{\circ} 103$ (p. 83) de este tratado escatológico, otra tradición recogida por Al-Qurtubi en su al-tadkira, 385, en la que se describe lo que hace el fuego con los condenados en cada uno de los siete pisos infernales. El segundo de estos pisos se llama Làza porque "arranca el cuero cabelludo".

${ }^{51}$ Los tormentos cuyo objeto es la cabellera del prescito tienen su origen en algunos hadices musulmanes, donde van asociados comúnmente, como se ve en multitud de muestras escultóricas románicas, al pecado de la lujuria (cf. Í̃̃IgueZ Almech, F., "La escatología musulmana en los capiteles románicos", en Príncipe de Viana, n. ${ }^{\text {ss }}$ 108-109, Pamplona, 1967, pp. 265-275).

52 El primero se halla en la escena de la Visión de los cuatro jinetes (fol. 135). Su color es negro y lleva alas; el segundo (fol. 17v del Beato gerundense) es áptero como el que aquí nos ocupa, y las serpientes culebrean por sus brazos.

53 “... Hay setenta mil dragones y otros tantos escorpiones, de los que habéis oído hablar anteriormente. El infierno está todo él lleno de bestias de muy diversas clases y cada una de ellas provoca en los pecadores, setenta mil clases de tormentos" (Libro de la escala de Mahoma, LXXI). 
Es evidente que nos hallamos ante una escenografía esencialmente hispánica, donde destaca la clara (aunque no única) inspiración musulmana de su imaginería; inspiración asumida como propia a lo largo de siglos de permanente ósmosis peninsular, pues los mismos cristianos, tan denostadores de los rasgos mezquinos y groseramente sensuales del paraíso coránico, asumieron sin demasiados problemas las refinadas sevicias orientales, necesitados como estaban de completar, sin colisionar con la ortodoxia, la paupérrima visión que del trasmundo les suministraba su propia literatura canónica. Esta inspiración muslímica se deja traslucir en el perfil serpentiforme y circular del infierno ${ }^{54}$, en el ataque de las sierpes como tormento, y en la presencia de animales y seres andrófagos. En la gran figura del Antiguo Enemigo, encontramos, además, la acusada defedación en la que los Beatos venían poniendo tanto empeño desde mediados del siglo X.

Faltaría, por último, explicar el significado de la ya comentada franja: la que atraviesa la escena que analizamos. El sin sentido de su presencia tiene para nosotros una sola justificación, que concuerda por otra parte con su, a nuestro parecer, evidente origen miniado: la confección de una gran inicial o letra capitular; concretamente una $\mathrm{D}$, que obviamente correspondería con la $\mathrm{D}$ de Diabolus. En efecto, el dragón-serpiente es, como señala Yarza, el animal "que por su esencia imaginaria y por su forma, mejor se presta a plegarse a cualquier rasgo de la letra" 55 ; por eso, según el mismo autor, es raro el manuscrito que se sustrae a su repetida utilización ${ }^{56}$. La franja sería, pues, en este caso, el recurso gráfico (tal vez demasiado convencional y, por ende, figurativamente poco imaginativo) utilizado para definir el trazo vertical de la gran D mayúscula ${ }^{57}$.

ANTONIO De ÁviLA JuÁREZ

54 "Ibn Arabi dice que los sufíes españoles de la escuela de Ibn Masarra imaginaban el infierno como la figura de una serpiente" (cf. Abu I-Hasan al-As'ari, Kitab sayarat al-yaqin. Tratado de escatología musulmana, p. 26, not. 50).

55 YARZA LuACES, J., op. cit., p. 34.

56 "Quizá se explique porque la forma ondulada y las posibilidades de adaptación flexible a cualquier forma van mejor a la línea que al modelado. Lo cierto es que apenas hay manuscrito que no disponga de tres o cuatro de estos animales cuando menos" (cf. YARZA LuACES, J., op. cit., p. 169).

${ }^{57}$ Corroborado por el hecho, ya comentado anteriormente, de que la franja no rebasa los límites de la curva, es decir, del arco que describe la serpiente-dragón. 